\title{
Pearls \& Oy-sters: Isolated prosopagnosia as the presenting complaint in glioblastoma
}

\section{The face of deception}

Saurav Das, MD, and Eric Burton, MD

Neurolog ${ }^{\circledR}$ 2019;93:642-644. doi:10.1212/WNL.0000000000008204
Correspondence

Dr. Das

saurav.das@louisville.edu

\section{Pearls}

- Prosopagnosia localizes to the fusiform gyrus in the medial temporal lobe and occurs from bilateral lesions or less frequently from unilateral lesions involving the right side alone.

- Commonly reported lesions resulting in prosopagnosia include strokes and seizures involving the above regions, while tumors are a rarely reported cause.

- Facial recognition is a more complex process than previously thought. Core face recognition network in the brain includes the occipital face area, the fusiform face area, and the face-selective posterior superior temporal sulcus.

\section{Oy-sters}

- An isolated cognitive deficit like prosopagnosia may be the first presenting symptom in patients with primary brain tumors or metastatic disease that involves the bilateral medial temporal lobes or the right medial temporal lobe alone.

- Detailed neurologic and ophthalmologic examinations can have localization value, as in this case of rare neuro-behavioral syndrome associated with a focal brain lesion.

Prosopagnosia is the inability to recognize familiar faces. Patients with this disorder usually retain otherwise normal visual function and are generally able to recognize other objects. Typically patients are distressed because they cannot recognize family, friends, and public figures by face.

Lesions in the medial temporal lobe, specifically the temporo-occipital area (fusiform gyrus), are sufficient to cause the deficit. Interestingly, both bilateral and unilateral right-sided lesions have been associated with prosopagnosia. Although in theory any pathologic process in these anatomic locations could result in this disorder, tumor is a rarely reported cause. Here we describe a patient diagnosed with a glioblastoma who presented with acute prosopagnosia.

\section{Case report}

A 69-year-old right-handed woman presented with subacute onset of visual distortion and frequent feeling of lightheadedness without other neurologic symptoms. She reported that one night while she was watching television, it appeared that several older people had facelifts and everyone's face looked wider, particularly around the jawline. Familiar news commentators looked unlike themselves and a presidential candidate's face was distorted. Over the next 2 days, it became more difficult to recognize people, even if they were very well known to her. While looking at family photographs, everyone looked alike. At one point, she met an old family friend that she could only identify after he spoke. Heavy people appeared to have lost weight and normally slim people appeared to be heavier. She could no longer discern attractive and less attractive people. However, her reading was not affected during this period.

From the Department of Neurology (S.D.), University of Louisville School of Medicine, KY; and Neuro-oncology Branch (E.B.), National Cancer Institute, NIH, Bethesda, MD. Go to Neurology.org/N for full disclosures. Funding information and disclosures deemed relevant by the authors, if any, are provided at the end of the article. 


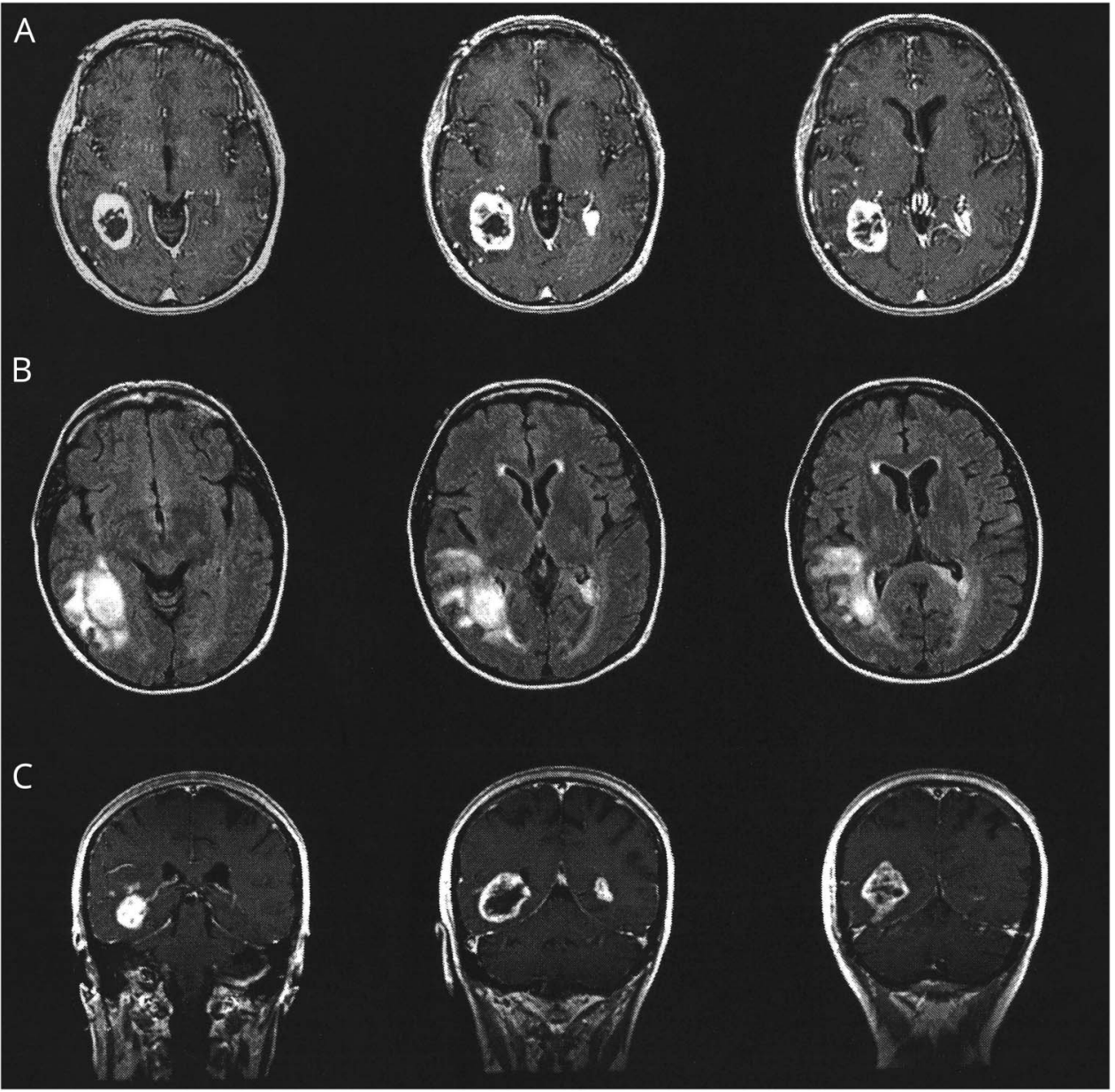

Axial contrast-enhanced spoiled gradient recalled images $(A)$, axial fluid-attenuated recovery images (B), and coronal contrast-enhanced T1-weighted spin echo images (C) demonstrate multiple contrast-enhancing masses involving the right temporo-occipital lobe and left parietal atrial region. The dominant mass in the right temporo-occipital lobe is associated with moderate surrounding edema and mass effect. This lesion was biopsied and revealed glioblastoma multiforme.
The patient was seen by her family physician and by her ophthalmologist 6 days after symptom onset. The family physician noted no overt neurologic changes on examination. The ophthalmologic examination showed $20 / 20$ visual acuity with corrected vision, no visual field deficits, and normal slitlamp, funduscopic, and tonometric examination.

The patient was referred for an MRI scan of the brain to evaluate for any intracranial abnormalities. The MRI showed changes consistent with multi focal bihemispheric high-grade glioma (figure). There was a large enhancing area with surrounding edema in the right temporo-occipital lobe. This was the most prominent site. A second enhancing lesion was located at the left parietal white matter with extension in splenium of corpus callosum. There was also abnormal signal seen on T2 fluid-attenuated inversion recovery image involving the left frontal gyri. Based on these findings, the patient was referred for biopsy. At the tertiary institution where she was referred for biopsy, her neurologic examination was significant only for left visual inattention to simultaneous bilateral stimuli, suggesting a left hemispatial neglect, in addition to prosopagnosia. A biopsy of the right temporo-occipital tumor revealed glioblastoma multiforme. The patient was then referred for radiation and chemotherapy.

Following steroid treatment with subsequent chemoradiation, the patient's ability to recognize faces returned. Follow-up brain imaging showed reduction in surrounding edema and tumor size of the right-sided lesion.

\section{Discussion}

Glioblastoma multiforme is the most common primary malignant glial neoplasm in adults. It is classified as a WHO grade IV astrocytoma with an incidence rate of 3.69 per 100,000 persons in the United States. The median survival is approximately 9-15 months. Patients' presenting symptoms are based on the tumor's anatomic location in the brain.

In this patient, the location of this tumor was predominantly in the medial right temporo-occipital lobe, causing prosopagnosia. Although there was a lesion involving the left atrial region, it spared the left fusiform gyrus. Therefore, it is unclear if the left-sided lesions contributed to this patient's deficit. 
Bilateral medial temporo-occipital lesions have been reported at autopsy in patients with prosopagnosia. However, there is also evidence that a unilateral right fusiform gyrus involvement may result in prosopagnosia. ${ }^{1}$ This suggests complete lateralization of face-specific processing in some patients but not in others.

Functional MRI studies have shown that facial recognition is a complex process that involves several specialized areas in the brain that work through complex interactions. For example, identifying facial motion not only enhances the understanding of facial expression, but can also improve the perception of other face aspects like speech comprehension (as best evidenced in the hearing impaired), in addition to the perception of gender and identity. ${ }^{2}$ This process of integrating the additional cues from facial movement with facial form is termed static-dynamic integration. Also, the traditional belief that the cortical cascade of visual processing is a bottom-up process initiating in the occipital cortex, and then projecting to prefrontal cortex for higherlevel processing only after the object is identified completely in the fusiform gyrus, is changing. There is evidence that a partially analyzed version of visual input is projected to the orbitofrontal gyrus, which then activates expectations of the most likely interpretation of the input image. This "initial guess" is projected back to the temporal cortex before the face is completely recognized in a process called "top-down integration". ${ }^{3}$ Zhao et al. ${ }^{4}$ classify the brain regions associated with face recognition into 2 groups; namely, the core and the extended face network. In this proposed model, the core network includes the occipital face area, the fusiform face area, and the face-selective posterior superior temporal sulcus. The extended face network includes the rest of the face-responsive regions such as anterior temporal lobe, the inferior frontal gyrus, the orbital frontal cortex and the amygdala. These areas interact with one another to serve several specialized functions, namely, integration of staticdynamic information, retrieval of personal information, and top-down facilitation.

Prosopagnosia can be developmental or acquired. Some of the most common causes of acquired prosopagnosia include destructive lesions like posterior cerebral artery stroke or hematoma. A PubMed search for the MeSH terms "prosopagnosia" and "tumor" yields 8 publications between 1990 and 2019. These publications can be broadly classified into 3 categories. The first group includes prosopagnosia caused directly due to tumors involving the right temporal lobe, for example, astrocytoma or lepto-meningeal metastases. ${ }^{5}$ The second includes a few patients who did not have prosopagnosia at presentation, but developed prosopagnosia as a transient symptom following treatment of different pathologies involving the right temporo-occipital lobe; that is, resection of a low-grade glioma, arteriovenous malformation treatment, or intrathecal chemotherapy for leptomeningeal metastases involving this region. ${ }^{6-8}$ The third group of papers, interestingly, includes tumors outside the CNS. For example, ovarian tumors related to mGLUR-5 antibodies or anti-NMDA receptor antibodies have been reported to cause limbic encephalitis, which can present with prosopagnosia. $^{9,10}$

The location of this patient's tumor is consistent with other reports of a right medial temporo-occipital lesion resulting in prosopagnosia. It is important to be mindful that isolated cognitive deficits like prosopagnosia can be the first presenting symptom of a localized brain tumor.

\section{Study funding}

No targeted funding reported.

\section{Disclosure}

The authors report no disclosures relevant to the manuscript. Go to Neurology.org/N for full disclosures.

\section{Appendix Authors}

\begin{tabular}{llll}
\hline Name & Location & Role & Contribution \\
\hline $\begin{array}{l}\text { Saurav } \\
\text { Das, MD }\end{array}$ & $\begin{array}{l}\text { University of } \\
\text { Louisville, KY }\end{array}$ & Author & $\begin{array}{l}\text { Conceptualization and } \\
\text { manuscript writing }\end{array}$ \\
\hline $\begin{array}{l}\text { Eric } \\
\text { Burton, } \\
\text { MD }\end{array}$ & Neuro-oncology & Author & $\begin{array}{l}\text { Patient care, } \\
\text { conceptualization and } \\
\text { Bethesda, MD }\end{array}$ \\
\hline
\end{tabular}

\section{References}

1. Landis T, Cummings JL, Christen L, Bogen JE, Imhof HG. Are unilateral right posterior cerebral lesions sufficient to cause prosopagnosia? Clinical and radiological findings in six additional patients. Cortex 1986;22:243-252.

2. Dobs K, Bülthoff I, Schultz J. Use and usefulness of dynamic face stimuli for face perception studies-a review of behavioral findings and methodology. Front Psychol 2018;9:1355.

3. Bar M. A cortical mechanism for triggering top-down facilitation in visual object recognition. J Cogn Neurosci 2003;15:600-609.

4. Zhao Y, Zhen Z, Liu X, Song Y, Liu J. The neural network for face recognition: insights from an fMRI study on developmental prosopagnosia. Neuroimage 2018;169: 151-161.

5. Anderson CA, Woodcock JH, Filley CM. Transient prosopagnosia with right temporal astrocytoma. J Neuropsychiatry Clin Neurosci 2016;28:e13-e14.

6. Miura M, Iijima N, Hayashida K, Kitazawa K, Ishii K, Ohara S. Case of leptomeningeal carcinomatosis effectively treated with intrathecal chemotherapy using ventriculoperitoneal shunt. Rinsho Shinkeigaku 2006;46:404-409.

7. Inoue $\mathrm{S}$, Kondoh $\mathrm{T}$, Nishihara M, Hosoda $\mathrm{K}$, Kohmura E. Transient prosopagnosia after removal of a tumor in the right occipito-temporal cortex: a case report. No Shinkei Geka 2008;36:1023-1027.

8. Suzuki K, Yamadori A, Takase S, Nagamine Y, Itoyama Y. Transient prosopagnosia and lasting topographical disorientation after the total removal of a right occipital arteriovenous malformation. Rinsho Shinkeigaku 1996;36:1114-1117.

9. Sawamura H, Yamamoto T, Ohtomo R, Bannai T, Wakakura M, Tsuji S. Anti-NMDA receptor encephalitis associated with transient cerebral dyschromatopsia, prosopagnosia, and lack of stereopsis. J Neuroophthalmol 2014;34:144-148.

10. Prüss H, Rothkirch M, Kopp U, et al. Limbic encephalitis with mGluR5 antibodies and immunotherapy-responsive prosopagnosia. Neurology 2014;83:1384-1386. 


\section{Neurology}

Pearls \& Oy-sters: Isolated prosopagnosia as the presenting complaint in glioblastoma: The face of deception

Saurav Das and Eric Burton

Neurology 2019;93;642-644

DOI 10.1212/WNL.0000000000008204

This information is current as of September 30, 2019

\section{Updated Information \&} Services

References

Subspecialty Collections

Permissions \& Licensing

Reprints including high resolution figures, can be found at: http://n.neurology.org/content/93/14/642.full

This article cites 10 articles, 1 of which you can access for free at: http://n.neurology.org/content/93/14/642.full\#ref-list-1

This article, along with others on similar topics, appears in the following collection(s):

Agnosia

http://n.neurology.org/cgi/collection/agnosia

All Clinical Neurology

http://n.neurology.org/cgi/collection/all_clinical_neurology

Primary brain tumor

http://n.neurology.org/cgi/collection/primary_brain_tumor

Information about reproducing this article in parts (figures,tables) or in its entirety can be found online at:

http://www.neurology.org/about/about_the_journal\#permissions

Information about ordering reprints can be found online:

http://n.neurology.org/subscribers/advertise

Neurology ${ }^{\circledR}$ is the official journal of the American Academy of Neurology. Published continuously since 1951, it is now a weekly with 48 issues per year. Copyright () 2019 American Academy of Neurology. All rights reserved. Print ISSN: 0028-3878. Online ISSN: 1526-632X.

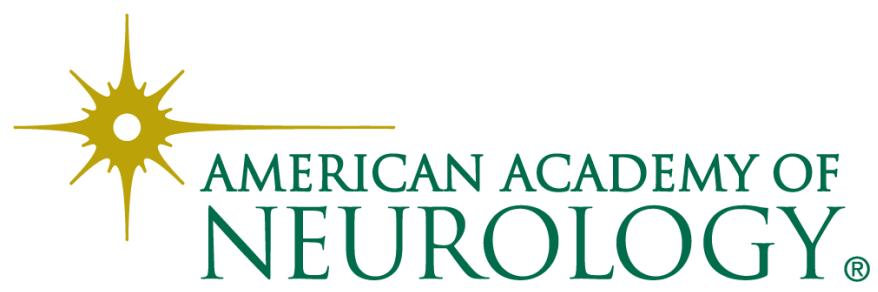

